\title{
Comprehensive Analysis with Enhanced Resolution of HAWT Blade using CFD
}

\author{
Amjith Lilly RAVEENDRAN* and Bavanish BALA \\ Department of Mechanical Engineering, Noorul Islam Center for Higher Education Kumaracoil, \\ Tamilnadu, India
}

('Corresponding author's e-mail: amjithlr2021@gmail.com)

Received: 30 March 2021, Revised: 15 May 2021, Accepted: 22 May 2021

\begin{abstract}
Energy is an important aspect for all countries. Due to the overexploitation of resources, nonrenewable resources, such as fossil fuels, are depleting day by day. This calls for alternative power sources, such as wind energy. Wind energy is a clean and inexhaustible source of energy. One of the ways of harvesting this energy is using wind turbines, which transform the kinetic energy of wind into electrical power output. Wind turbines face many problems, such as low wind hours, design issues, and so on.

The main focus of this work is to find the optimum blade angle of turbine blades, in order to produce the maximum power output, even at low wind hours. In this study, CFD analysis is done on a 5 MW wind turbine blade at wind velocities 3, 12.5 and $25 \mathrm{~m} / \mathrm{s}$, which are the cut in, rated, and cut out velocities of wind turbines, respectively. The range of angles under consideration varies from 20 to $89^{\circ}$. A 3D model of the blade is analyzed using ANSYS Fluent 19.0. The optimum blade angle is identified, and the characteristics of the curves of blade angles, with respect to different parameters, are obtained.
\end{abstract}

Keywords: Renewable energy, Blade element momentum theory (BEM), Computational fluid dynamics (CFD), Blade angle, Horizontal axis wind turbine (HAWT)

\section{Introduction}

Wind is the $2^{\text {nd }}$ largest renewable energy source for power generation. Wind power produced more than $5 \%$ of global electricity in 2018, with 591 GW of global capacity. In 2019, wind installed capacity reached $620 \mathrm{GW}$ [1]. Although people have harnessed the energy generated by the movement of air for hundreds of years, modern turbines reflect significant technological advances over early windmills and turbines from just 100 years ago.

Wind turbine power production depends on the interaction between turbine blades and the wind [2]. Depending on the wind turbine rotor orientation, there are 2 types of wind turbines; horizontal axis wind turbines (HAWT) and vertical axis wind turbines (VAWT). Initially, vertical axis wind turbines were considered to be more accurate because of their omnidirectionality and because the power generating equipment was located on the tower, to lower loads. The design failed, because the rotors were not efficient, and the huge weight in the structure caused metal fatigue problems [3]. In horizontal axis wind turbines, rotor axis is parallel to horizontal axis. They are more efficient compared to their counterpart. Although bladeless versions are more cost efficient, offshore horizontal axis wind turbines (HAWT) produce more energy at lower wind speeds, due to the ratio between power usage to power output of approximately $80 \%$ for bladed turbines and approximately $70 \%$ for bladeless turbines. Three-bladed turbines are the most prominently used, because they have both an odd number and a small number of blades [28]. Because HAWTs generate energy through the full rotation of their blades due to their perpendicular motion, they are the most efficient type of turbine. If there is too little wind, and the blades 
are moving too slowly, the wind turbine no longer produces electricity. The turbine starts to create power at what is known as the cut-in speed. Power output continues to grow as the wind increases.

According to wind turbine capacity, HAWTS are classified as small wind turbines, medium wind turbines, and large wind turbines.

The aerodynamic design optimization of a wind turbine includes the selection of chord, twist distribution, and blade angle to reach maximum efficiency. There is a need for an analysis tool to predict wind turbine performance and to use in the optimization process. This analysis tool must be accurate and consider all the involved physical phenomena, while being fast, so as to be used in the optimization process [4]. There have been different aerodynamic methods developed for wind turbines, such as blade element momentum theory (BEM) and computational fluid dynamics (CFD). Among different numerical methods, the BEM theory has low computing cost and acceptable accuracy, whereas CFD has greater accuracy but higher computing cost, especially in the case of the very large and lengthy blades of a 5MW wind turbine [5].

CFD helps to study flow properties non-invasively and allows researchers to study process variables at inaccessible locations, such as inside a hot furnace. Carrying out test simulations can also reduce the number of designs to be tested experimentally for final inspection [6]. The contributions to theoretical fluid dynamics started in the late $17^{\text {th }}$ century by the introduction of Newton's Laws of Motion [7]. Further significant work was done in the $18^{\text {th }}$ and $19^{\text {th }}$ centuries, when the Navier-Stokes and Euler equations were derived. The $1^{\text {st }}$ complex fluid dynamics calculations were solved by hand by Richardson in 1910 and included about 2000 operations every week [8]. These equations are coupled and were relatively difficult to solve, so the use of computers to solve them was the basis for the development of CFD. Though the time at which CFD started is debatable, the use of commercial code started around the 1980s [9]. Computational Fluid Dynamics (CFD) offers the best alternative to direct measurement [10]. The computational domain is divided into different regions, each one solved by the proper approach: Navier-Stokes solution near the blades, potential flow representation on the outer field, and a collection of vortex methods for modeling the vorticity field [11].Finite element method is the most popular discretization method in CFD. This method divides the main domain into control volumes and then integrates the equations over each control volume [12]. The result from CFD analysis is applied as a load to the mechanical analysis and, if the result is passed back to the CFD, it is called 2-way fluid structure interaction (FSI) or, otherwise, 1 way FSI [13]. The steady flow field around an isolated rotor of a middle-sized HAWT is predicted in a non-inertial reference frame, using the Spalart-Allmaras turbulence models for closure, and specifying a constant axial wind velocity at the inlet [14]. Various researchers have simulated the flow past NREL turbines by solving the Navier-Stokes equations using CFD technique. As the complete flow field is simulated, the predictions obtained by this method are more accurate than those obtained by the BEM method [15].

It is known that the blade angles play a major role in the efficiency of wind turbines. In this work, the optimum blade is identified analyzing the blade through different blade angles and finding out the optimum angle using CFD analysis.

\section{Materials and methods}

The effect of blade angles on the performance of a HAWT is studied at wind velocities 3, 12.5 and $25 \mathrm{~m} / \mathrm{s}$, which are the cut in, rated, and cut out velocities of the wind turbine, respectively. Blade angles provide ranges from 20 to $89^{\circ}$. A steady state CFD analysis is used. The flow of wind is perpendicular to the plane of rotation of the turbine blades. The turbine has a power rating of $5 \mathrm{MW}$. The blade profile has DU40, DU35, DU25, DU21 and NACA 64 airfoil coordinates. The chord length varies from 3.542 to $1.419 \mathrm{~m}$. The rotor diameter is 126 mand hub diameter is $6 \mathrm{~m}$. The entire blade length is twisted for different blade angles. The pressure and velocity distribution also changes for different blade angles, due to change in the profile of the airfoils. A schematic diagram of the airfoil section and the forces acting on it are shown in Figure 1. 


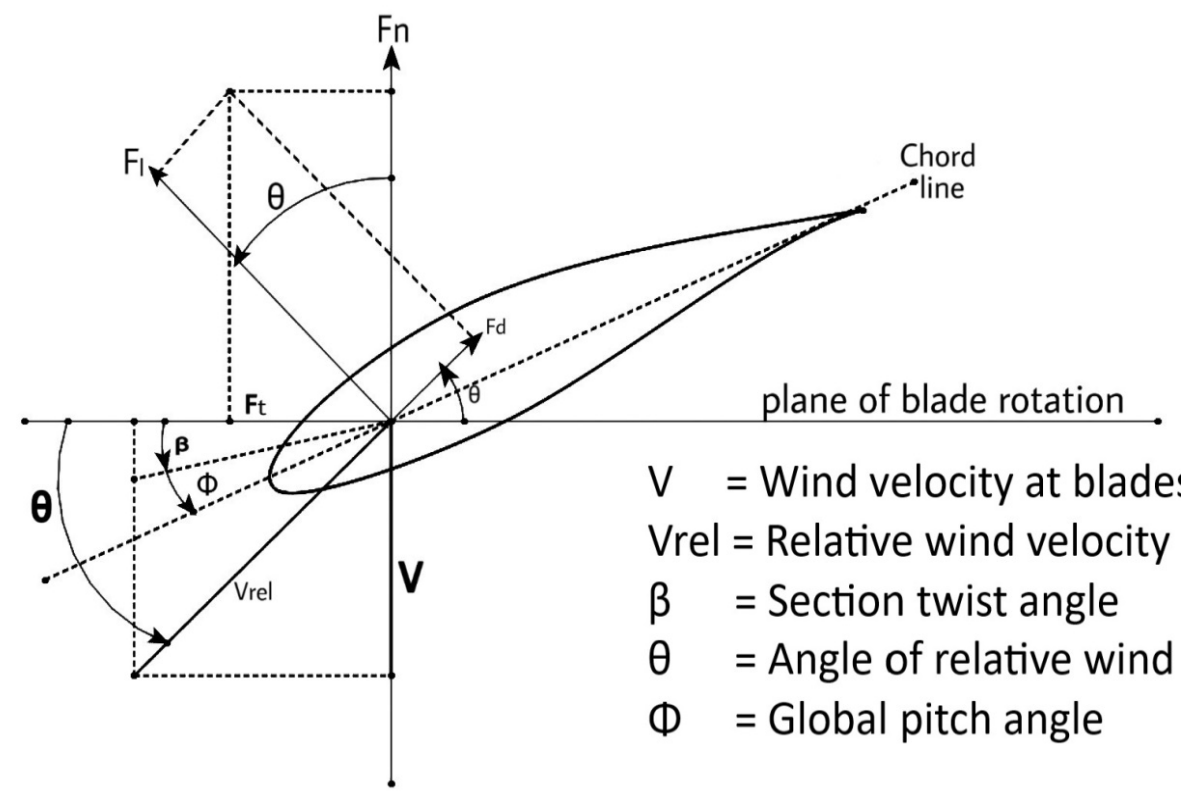

Figure 1 Airfoil section.

\section{Governing equations and parameters}

Wind turbine converts the kinetic energy of wind into electrical energy. The extractable power from the wind is given by,

$P_{\text {avail }}=\frac{1}{2} \rho \mathrm{AV}^{3} \mathrm{C}_{\mathrm{p}}$

Where $\rho$ is the density of air, A is the swept area of rotor, $\mathrm{V}$ is the velocity of wind, and $\mathrm{Cp}$ is the theoretical maximum coefficient of power for any wind turbine, called Betz limit.

The air flow past the fan blade is turbulent. The properties of air considered for the analysis are as follows:

Density, $\rho=1.225 \mathrm{~kg} / \mathrm{m}^{3}$

Dynamic viscosity, $\mu=1.7894 \times 10^{-5} \mathrm{~kg} / \mathrm{m}^{-\mathrm{s}}$

Tip speed ratio, TSR, is a dimensionless quantity, given by

$\mathrm{TSR}=$ speed of rotor speed at tip/wind speed

The solid boundaries are not assigned any material, since the analysis is focused on studying the flow characteristics, rather than the interaction of the structure with the fluid flow. The Reynolds number varies in the range of $1 \times 10^{6}$ and $4 \times 10^{6}$. The air flow past the fan blade is, therefore, turbulent, and the Spalart-Allmaras turbulence model is used, which solves the transport equation for the kinematic eddy viscosity.

The values for all other parameters set by ANSYS Fluent are retained as default. The solution is set to run for 2000 iterations for each angle from 20 to $89^{\circ}$. Intermediate result file generation is set for every 50 iterations to check for the correctness of solution generated at each step. 
Table 1Operating conditions.

\begin{tabular}{ll}
\hline Wind velocity & $3,12.5$ and $25 \mathrm{~m} / \mathrm{s}$ \\
Blade angles & 20 to $89^{\circ}$ \\
Turbine power rating & $5 \mathrm{MW}$ \\
Airfoil coordinates & DU40, DU35, DU25, DU21 and NACA 64 \\
Chord length & 3.542 to $1.419 \mathrm{~m}$ \\
Rotor diameter & $126 \mathrm{~m}$ \\
Hub diameter & $6 \mathrm{~m}$ \\
\hline
\end{tabular}

\section{Methodology}

The 3D model is regenerated in the design modeler and cleaned up, as required for geometric simplifications. The geometry cleanup helps in eliminating errors during analysis, which are due to irresolvable issues in the model. The 3D blade model is covered with a surrounding domain for flow, and the boundaries of the domain are determined by Boolean operations. The blade domain is subtracted from the entire domain for accurate setting up of the flow boundaries. Air inlet and outlet locations are preplanned, and provisions for the same in fluid domain boundaries are included. Steady flow analyses are conducted for incoming air flow at $12.5 \mathrm{~m} / \mathrm{s}$ for incident angles varying from 20 to $89^{\circ}$. The FE model (meshed model) is generated using an automatic sweep method with 4 noded elements and linear element order. The air flow inlet and outlet and blade boundaries are defined by selecting and naming them appropriately. The FE model is characterized by a total of 7,767,900 elements and 7,875,384 nodes. The mesh model is shown in Figure 2.
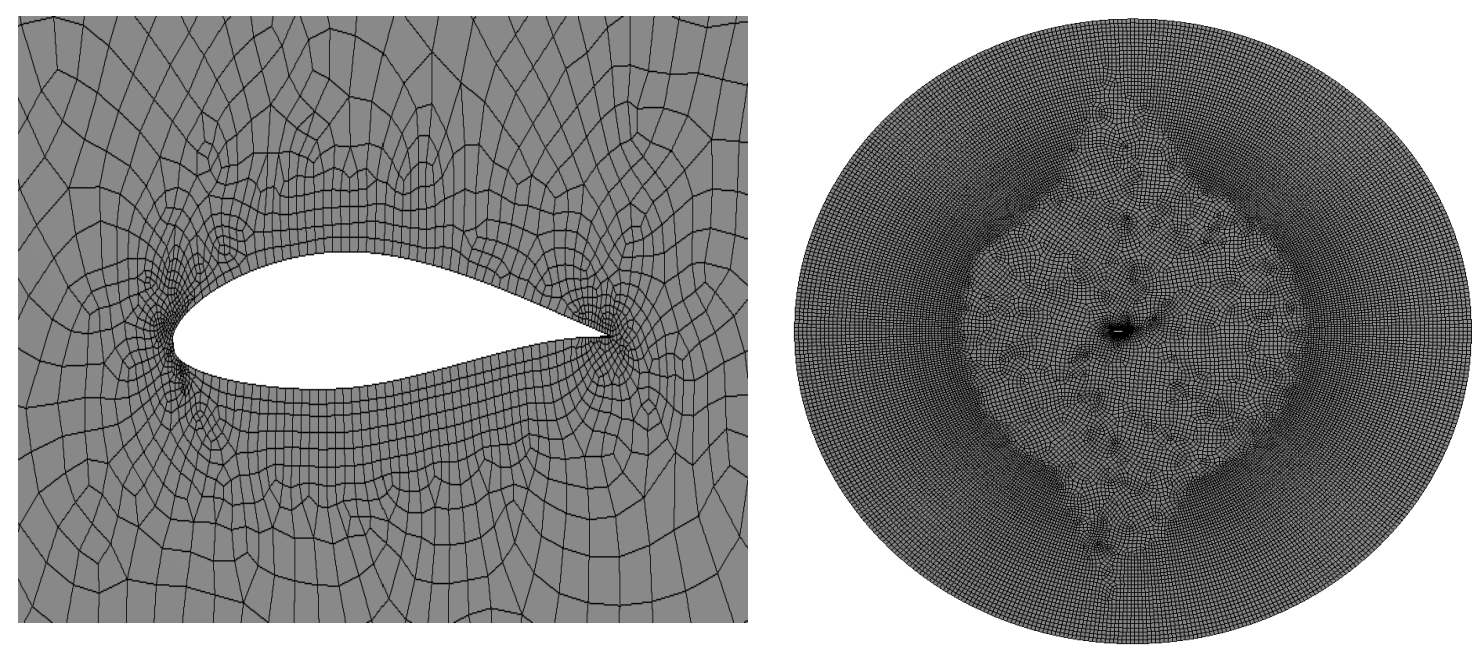

Figure 2 3D mesh of the wind turbine blade.

The FE mesh complies with the requirements for a CFD analysis, in terms of element quality parameters to acceptable levels. The FE model generation and the CFD analyses are performed on an 8core processor. Steady state CFD analyses are run for angles ranging from 20 to $89^{\circ}$ using ANSYS fluent. The net velocity of the incoming free stream air is kept constant at $3,12.5$ and $25 \mathrm{~m} / \mathrm{s}$ for each analysis. Stationary no-slip wall boundary conditions are applied to the fan blade surfaces. Velocity inlet boundary condition is defined for the inlet air flow face, and pressure outlet boundary condition is defined 
for the outlet face, of the domain. The air flow past the turbine blade induces drag in the $x$-direction and lift in the $y$-direction. The blade rotates with respect to the $x$-axis under the action of the forces induced by the wind. The above table shows the amount of lift, drag, moment generated, and the rotational speed at which the wind turbine shall be operated with respect to the angle of incidence of the free stream air.

\section{Results and discussion}

Steady state analysis of a turbine blade in ANSYS Fluent is done. The operating conditions are shown in Table 1. Pressure and velocity distributions obtained are discussed in detail. The lift, drag, and moment are also estimated for each angle of incidence, and characteristics are graphically plotted. Rotational speeds for desired output power for each angle of incidence are also estimated with respect to the torques produced. Pressure distributions at static and dynamic states are shown in Figure 3.
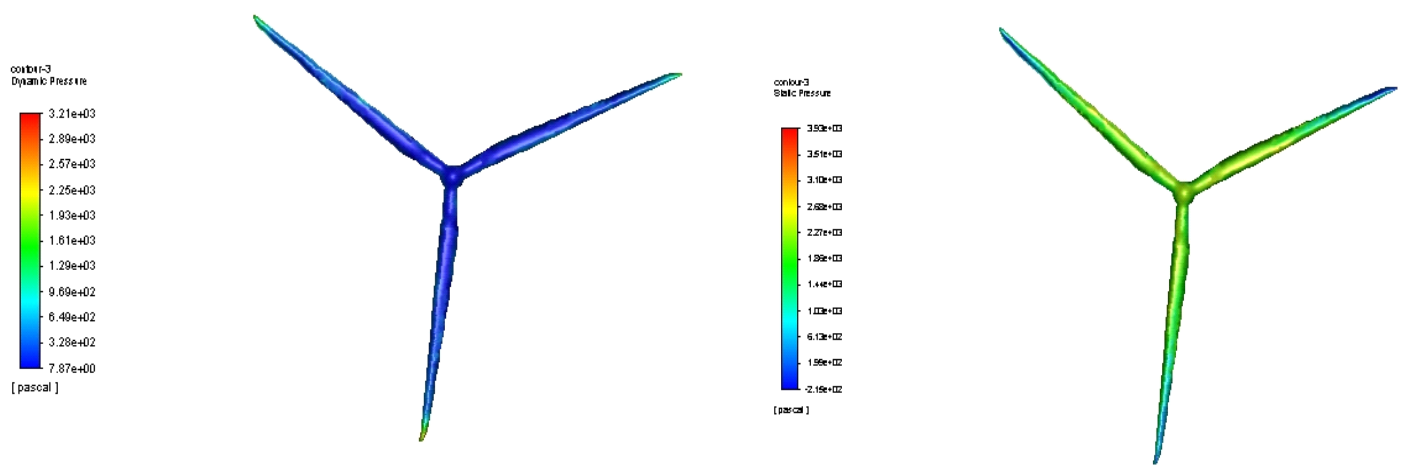

Figure 3 Pressure distributions at static and dynamic states.

The air flow around the fan blade induces pressure variations that drive the blade to produce power. The pressure distribution plots show the variation of pressure at different angles of incidence of air at the root portion of the fan blade. The boundary layers close to the fan blade surface are successfully captured with the mesh settings used. The pressure variations clearly show how the lift force is generated by the changing direction of the incident air. Pressure distribution at different angles is obtained, as shown in Figure 4 . 


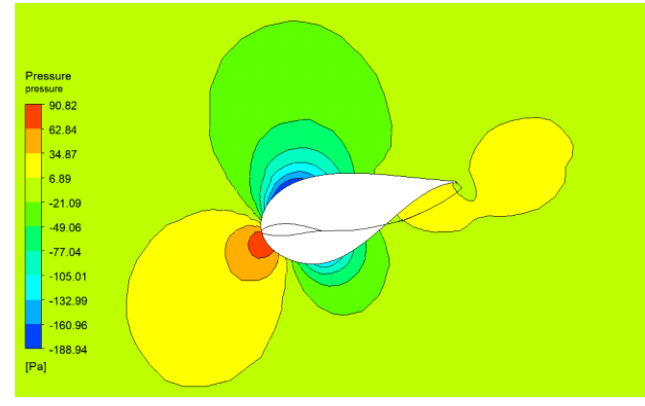

a. $20^{\circ}$

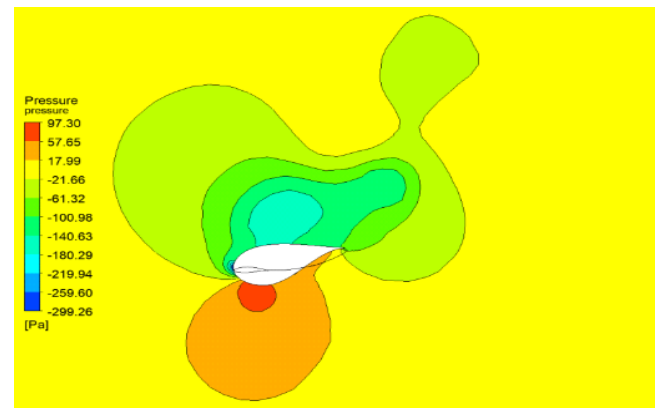

c. $60^{\circ}$

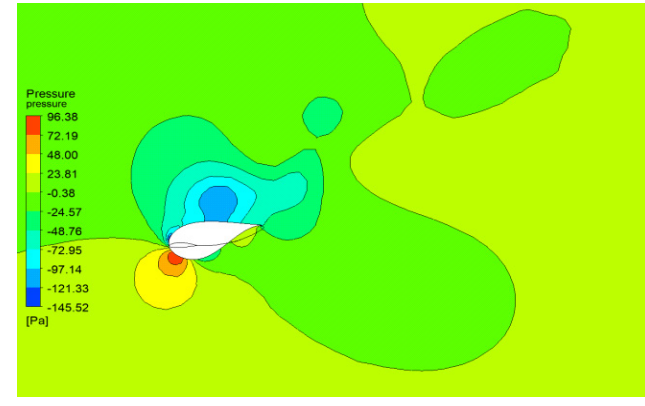

b. $40^{\circ}$

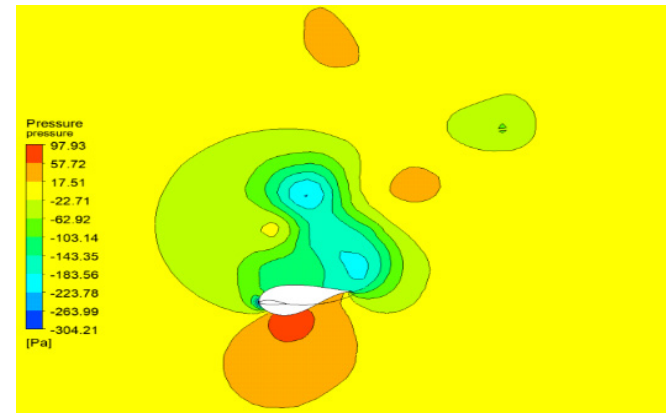

d. $82^{\circ}$

Figure 4 Pressure distributions at different angles.

The air flow velocity past the turbine blade is analyzed for understanding the fluctuations of flow. The formation of low pressure regions above the top surface and high pressure region indicate higher flow velocities at the bottom surface, and lower flow velocities at the top surface, of the turbine blade, owing to the formation of flow wakes at the low pressure regions below the airfoil profiles. Additionally, it is observed that the steadiness of flow is retained up to an angle of $30^{\circ}$, above which the eddy formations are observed behind the blade profile. Velocity distribution at different angles is obtained, as shown in Figure 5. 


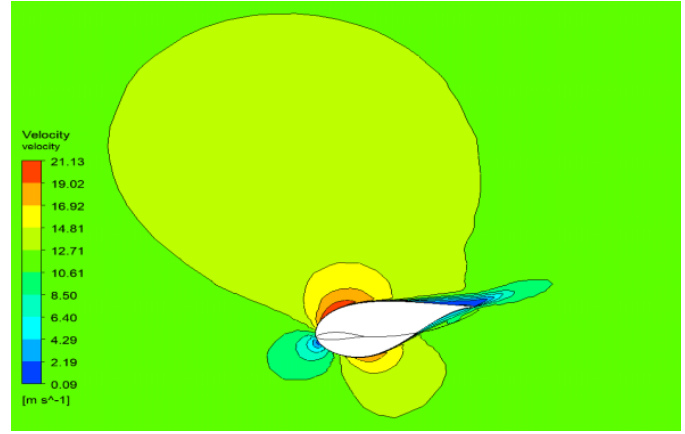

a. $20^{\circ}$

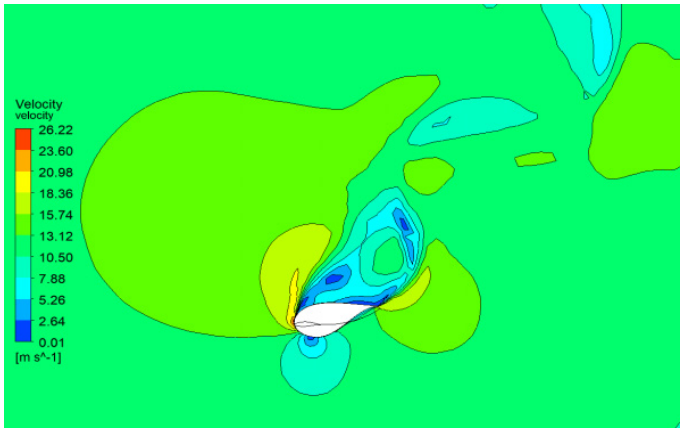

c. $60^{\circ}$

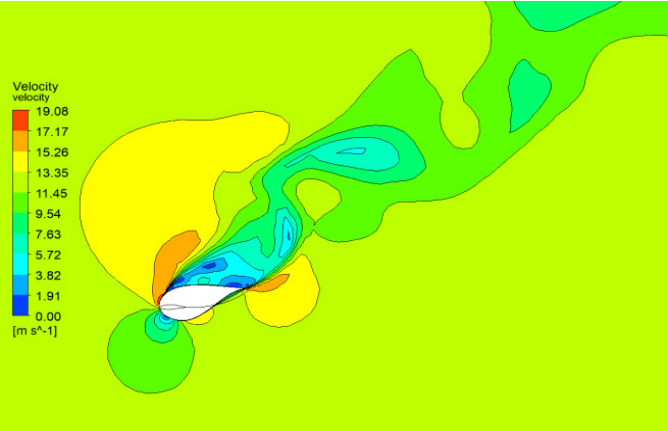

b. $40^{\circ}$

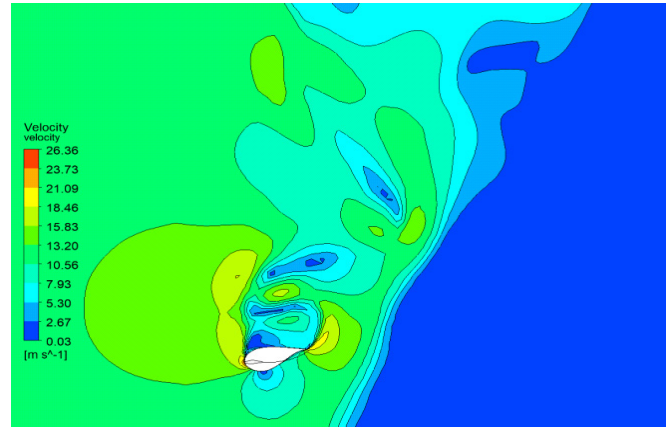

d. $82^{\circ}$

Figure 5 Velocity distributions at different angles.

The boundary layers close to the fan blade surface were successfully captured, with the mesh settings used at the root side, as well as the tip of the blade. It should be noted that the local pressure distribution along the blade span is different from the pressure distributions at the root and tip of the fan blade. Further, the local pressures at the root and tip sides are different, due to the differences in chord length at each airfoil section of the turbine blade. The generated solutions are reviewed for the correctness of solution pattern and for deriving the required set of outputs in a presentable form. CFD-Post is a freeware platform with ANSYS that is common for the post-processing of solution-generated results. CFD-Post is a very versatile platform for reviewing solution results and for generation of user-defined plots or parameter distribution plots, graphs, tabulations, animations, etc. CFD-Post is a robust postprocessing platform supporting a wide range of file formats and types of analyses, including fluid flow, heat transfer, structural, multi-physics, etc. Pressure and velocity contour plots are extracted at the wider root portion of the blade and the narrow tip portion of the blade for each angle, 20 to $89^{\circ}$. The drag and lift forces, as well as the turning moment, are derived using the expression-based calculators available in CFD-Post. The extracted forces and moments for each analysis are tabulated, and graphical representations are generated.

\section{Variation in moment}

In the early stage of simulation, as we can see in Figure 6, there is a gradual increase in the moment as the angles increases from 20 until $82^{\circ}$; then, there is a sudden decrease in the value of moment at 25 and $12.5 \mathrm{~m} / \mathrm{s}$ incident velocity, and it is almost constant at $3 \mathrm{~m} / \mathrm{s}$, as the change in values at different angles are less. 




Figure 6 Moment characteristics with respect to angle of incidence.

\section{Variation in coefficient of pressure}

Coefficient of pressure, shown in Figure 7, is the difference between local static pressure and freestream static pressure, non-dimensionalized by the free-stream dynamic pressure. Coefficient of pressure shows similar values until $70^{\circ}$ in both 25 and $12.5 \mathrm{~m} / \mathrm{s}$; then, it suddenly decreases at 80 , and then again increases, where it has almost the same values at $3 \mathrm{~m} / \mathrm{s}$ velocity. 


\section{COEFFICIENT PRESSURE VS ANGLE OF INCIDENCE}

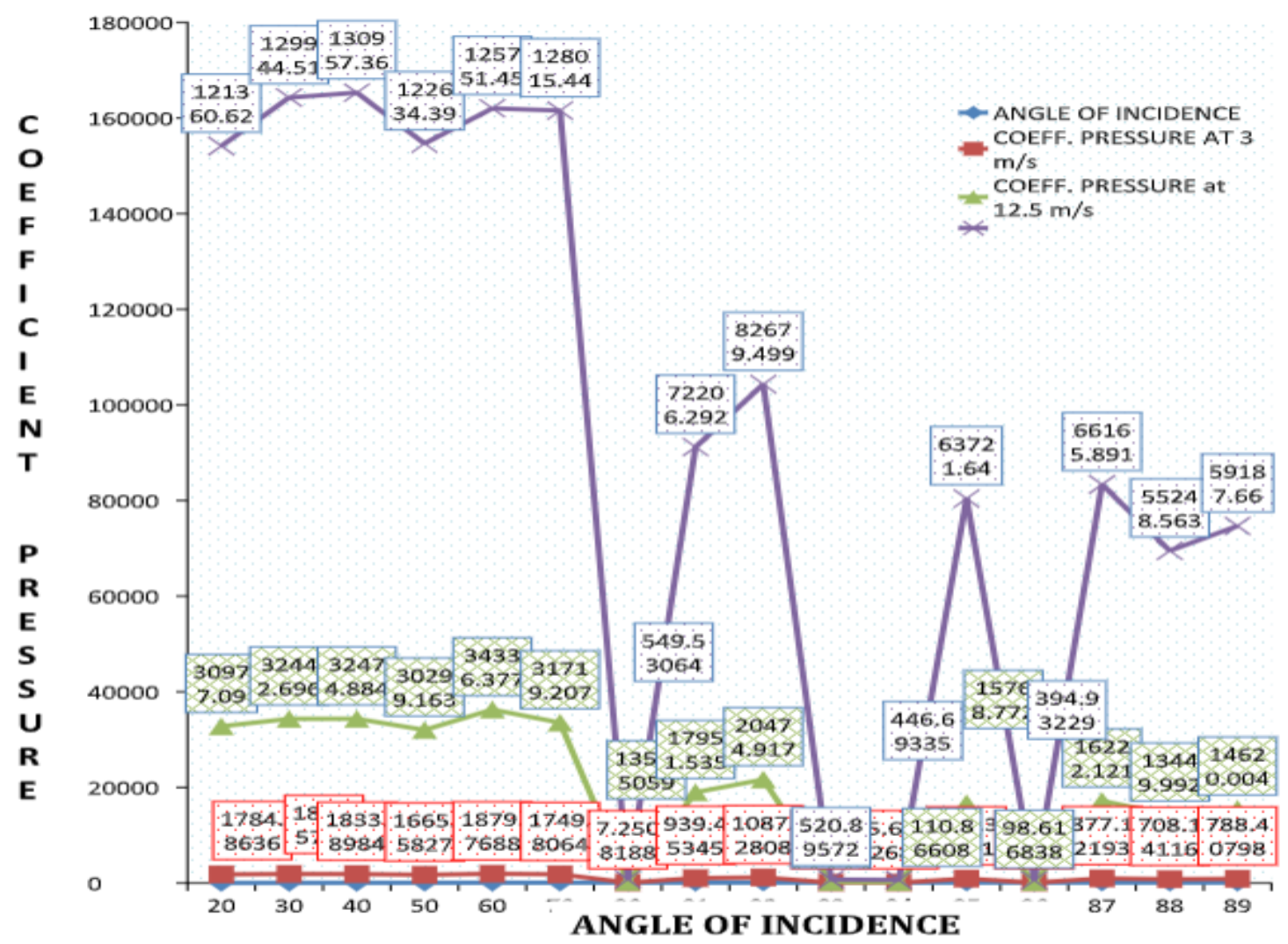

Figure7 Coefficient of pressure with respect to angle of incidence.

\section{Variation in coefficient of lift}

The coefficient of lift, shown in Figure 8, is a dimensionless coefficient that relates the lift generated by a lifting body to the fluid density around the body, the fluid velocity, and an associated reference area. At $3 \mathrm{~m} / \mathrm{s}$, free stream velocity coefficient of lift shows similar values at the beginning stages, then tends to fluctuate, but at 12.5 and $25 \mathrm{~m} / \mathrm{s}$, the values change drastically at the beginning, and suddenly decrease towards the end. 


\section{COEFFICIENT LIFT VS ANGLE OF INCIDENCE}

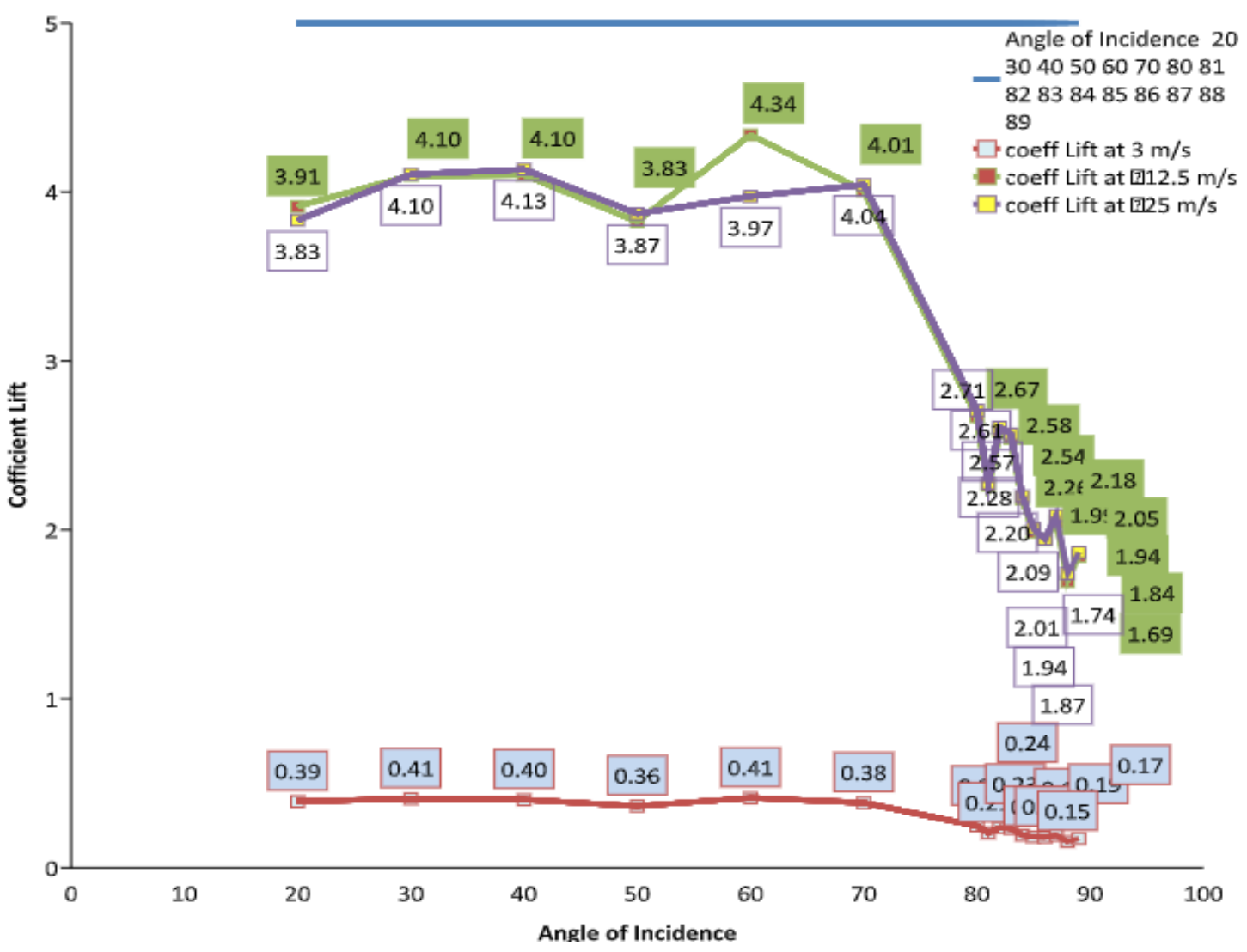

Figure8Coefficient of lift with respect to angle of incidence.

\section{Variation in coefficient of drag}

The coefficient of drag, shown in Figure 9, is used to quantify the drag or resistance of an object in a fluid environment. In this study, the drag coefficient shows a linear increase in the values going from 20 to $89^{\circ}$. This means that higher angle resistance to air flow increases due to the airfoil profile of turbine blades. At 12.5 and $25 \mathrm{~m} / \mathrm{s}$, the value of drag coefficient suddenly decreases at the beginning, and then gradually decreases, but at $3 \mathrm{~m} / \mathrm{s}$, it shows gradual increase. 


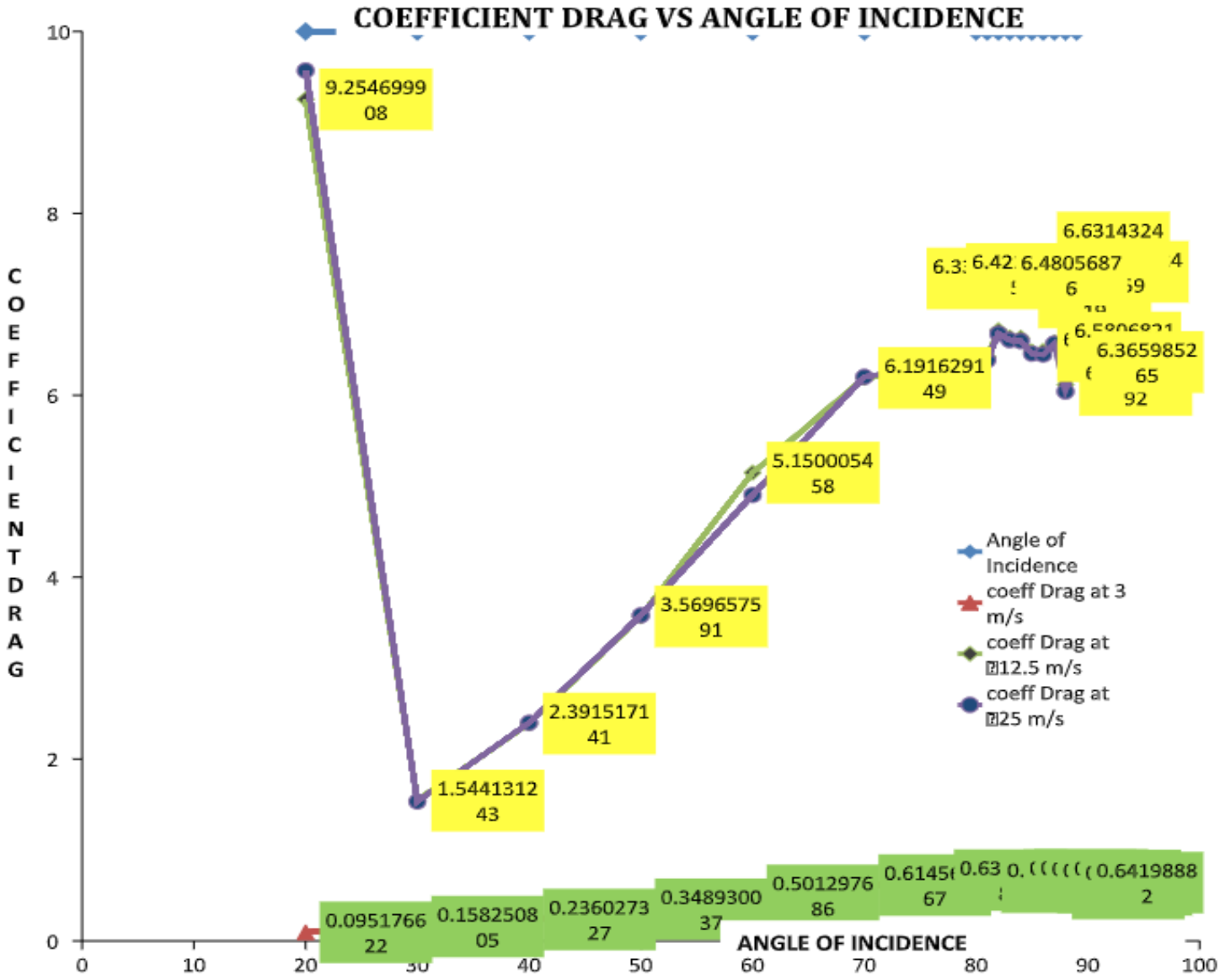

Figure9 Coefficient of drag with respect to angle of incidence.

\section{Conclusions}

The use of renewable energy sources has increased significantly in the past decade, due to the robust request for the sustainable protection of our environment. Among these renewable energies, the use of wind power has become the fastest growing energy technology in the world. The objective of the project was to find out an optimum tilt angle for a 5MW horizontal axis wind turbine blade, so that it delivers maximum power. To achieve this objective, steady state 3 dimensional turbulent flow simulations were performed for a NREL $5 \mathrm{MW}$ offshore baseline wind turbine. The analysis and post-processing were done in ANSYS Fluent. Tilt angles from 20 to $90^{\circ}$ were set as incident angles for the analysis process. Free stream velocity of air was selected to be $3,12.5$ and $25 \mathrm{~m} / \mathrm{s}$. We have plotted graphs on moment, coefficient of pressure, coefficient of lift, and coefficient of drag versus tilt. It was observed that, at all the incident wind velocities, the maximum momentum occurred at a tilt angle of $82^{\circ}$. Therefore, it can be concluded that a $5 \mathrm{MW}$ wind turbine could generate maximum power at $82^{\circ}$. 
http://wjst.wu.ac.th

\section{References}

[1] PK Nigam, N Tenguria and MK Pradhan. Review on design of horizontal axis wind turbine blades. Int. J. Res. Anal. Rev. 2018; 5, 871-8.

[2] S Rehman, MM Alam, LM Alhems and MM Rafique. Horizontal axis wind turbine blade design methodologies for efficiency enhancement: A review. Energies 2018; 11, 506.

[3] C Pavese, C Tibaldi, F Zahle and T Kim. Aeroelastic multidisciplinary design optimization of a swept wind turbine blade. Wind Energ. 2017; 20, 1941-53.

[4] U Fernandez-Gamiz, E Zulueta, A Boyano, JA Ramos-Hernanz and JM Lopez-Guede. Microtab design and implementation on a 5 MW wind turbine. Appl. Sci. 2017; 7, 536.

[5] W Hu, KK Choi and H Cho. Reliability-based design optimization of wind turbine blades for fatigue life under dynamic wind load uncertainty. Struct. Multidiscip. Optim. 2016; 54, 953-70.

[6] MA Elfarra, N Sezer-Uzol and IS Akmandor. NREL VI rotor blade: Numerical investigation and winglet design and optimization using CFD. Wind Energ. 2014; 17, 605-26.

[7] B Bavanish and K Thyagarajan. Optimization of power coefficient on a horizontal axis wind turbine using BEM theory. Renew. Sustain. Energ. Rev. 2013; 26, 169-82.

[8] B Bavanish and K Thyagarajan. Aerodynamic performance analysis of a flat plate HAWT. Int. J. Recent Tech. Eng. 2012; 1, 181-91.

[9] J Chen, H Yang, M Yang, $\mathrm{H} \mathrm{Xu}$ and $\mathrm{Z} \mathrm{Hu}$. A comprehensive review of the theoretical approaches for the airfoil design of lift-type vertical axis wind turbine. Renew. Sustain. Energ. Rev. 2015; 51, 1709-20.

[10] W Han, P Yan, W Han and Y He. Design of wind turbines with shroud and lobed ejectors for efficient utilization of low-grade wind energy. Energy 2015; 89, 687-701.

[11] T Yavuz, E Koc, B Kilkis, O Erol, C Balas and T Aydemir. Performance analysis of the airfoil-slat arrangements for hydro and wind turbine applications. Renew. Energ. 2015; 74, 414-21.

[12] J Chang, W Zhu, A Fischer, NR García, J Madsen, J Chen and WZ Shen. Design and validation of the high performance and low noise CQU-DTU-LN1 airfoils. Wind Energ. 2014; 17, 1817-33.

[13] S Rajakumar and D Ravindran. Computational fluid dynamics of wind turbine blade at various angles of attack and low Reynolds number. Int. J. Eng. Sci. Tech. 2010; 2, 6474-84.

[14] K Badreddinne, H Ali and A David. Optimum project for horizontal axis wind turbine OPHWT. Renew. Energ. 2005; 30, 2019-43.

[15] J Jonkman, S Butterfield, W Musial and G Scott. Definition of a $5 \mathrm{MW}$ reference wind turbine for offshore system. Technical Report NREL/TP-500/38060, 2009. 